\title{
Technology for Equity and Social Justice in Education: Introduction to the Special Issue
}

\author{
Sherry Marx \\ Utah State University \\ U.S.A. \\ Yanghee Kim \\ Northern Illinois University \\ U.S.A
}

ABSTRACT: In this Introduction to the IJME Special Issue on Technology for Equity and Social Justice in Education, Sherry Marx and Yanghee Kim highlight key trends in technology education research that address issues of equity and multicultural education. Seven articles are introduced.

KEYWORDS: educational technology, multicultural education, computerassisted learning, inclusive design, interactive learning environments, learner diversity

References

Guest Editor Contact

The use of education technology to support equity and diversity is becoming more seamless than ever before. In the past, much research on technology and equity in education focused specifically on access to technology for historically marginalized populations, such as children of color, children with disabilities, and children in poverty. The current ubiquity of technology, evidenced in our everyday use of mobile devices, computers, and social networking sites, has promoted broadening user demographics, alleviating some concerns about equitable access to technology as a tool. Recent research expands the discussion of equity and diversity in education by attending to the means by which technology is taught and used, how it can enhance user identity, and what inequalities remain.

Innovative technology research is likely to position learners as active producers of computing and technology (Kim \& Searle, 2017), rather than mere consumers. Important studies in this area incorporate learners' cultural backgrounds into computing and encourage them to produce their own culturallyrich artifacts. Such efforts can help learners build identities as budding computer scientists and other science, technology, engineering, and mathematics (STEM) professionals (Shin, Barton, \& Johnson, 2017). Many efforts are underway to help more people identify with these traditionally less diverse professions (Marx, 2017).

At the same time, technology continues to play a significant role in increasing access to education and opportunity for historically underserved 
populations such as international migrants, women with children and domestic obligations, and people living in rural and remote areas. For such populations, technology can facilitate formal learning by making access to schooling possible. It can also impact informal learning by enhancing language and literacy skills through the everyday use of computers and mobile phones (Chib \& Wardoyo, 2018).

Computing devices also serve an important function as communication tool, enabling users across the world to meet together for conversation and cultural exchange. Extended contact between people of different cultural groups guided by multicultural educators has been shown to build friendships and reduce prejudices (Berger, Brenick, Lawrence, Coco, \& Abu-Raiya, 2018), an online strategy being used in areas of conflict. At the same time, technology can also be the means through which familiar social networks are maintained across diaspora.

Reflecting these trends, this special issue of IJME presents seven studies that examine technology for equity and social justice in different contexts across the globe for a variety of educational purposes.

In "Social Aspects of Learning with and through ICTs: Sámi People in the Circumpolar North," Outi Kaarina Laiti and Satu-Maarit Frangou examine information and communication technologies (ICTs) that combine traditional Sámi and Artic pedagogies, with the intention of making them relevant and useful to populations in the Circumpolar North. The authors find that social interactions are a key dimension of learning, even in the ICT context.

In "Connecting with Computer Science: Electronic Textile Portfolios as Ideational Resources for High School Students," Mia Shaw, Deborah Fields, and Yasmin Kafai examine the ways diverse high school students in California developed identities as computer scientists as they created and shared e-textiles. The authors focus on e-textile portfolios as ideational resources, a way of conceptualizing learners' interconnection with the world around them.

In "Equitable Engagement in STEM: Using E-textiles to Challenge the Positioning of Non-dominant Girls in School Science," Kristin Searle, Colby TofelGrehl, and Janet Breitenstein explore ways that working with sewable, programmable e-textiles impacted the self-perceptions and actions of two middle school girls from non-dominant communities in the United States as they navigated their place within science class. Findings indicate that the personalizable nature of e-textiles created a meaningful opportunity for students to engage in science class.

In "Online Collaboration between Arab and Jewish Students: Fear and Anxiety," Manal Yazbak Abu Ahmad and Elaine Hoter study Palestinian and Jewish students from five different colleges in Israel. Through a year-long online collaboration, students from varied religious and ethnic identities got to know one another and gradually reduced their apprehension about working together. Qualitative and quantitative measures are examined.

In "'A Very Difficult Topic to Talk about': Discursive Constructions of Cultural Practices in a USA-Turkey Telecollaboration," Baburhan Uzum, Bedrettin Yazan, 
Netta Avineri, and Sedat Akayoglu report on a collaborative exchange between teacher education classes in the U.S. and Turkey. In synchronous and asynchronous conversations, preservice teachers discussed social justice issues and made discourse choices that expressed cultures and communities with different levels of sophistication. The authors share implications for designing future telecollaborations that promote nuance and social justice.

In "Hearing Knowledge into Action: Mobilizing Sound for Multicultural Imaginaries," Candance Doerr-Stevens and Molly Buckley-Maruda focus on multimodal, sound-based data to explore how high school students in the United States harnessed elements of sound and music within radio podcasting. Findings reveal multivocal and divergent engagements in the sound editing process as well as multimodal struggles in which students leveraged sound to express nuanced views about racism, culture, and privilege.

In "Computing with Relevance and Purpose: A Review of Culturally Responsive Teaching in Computing Education," Jessica Morales-Chicas, Mauricio Castillo, Ireri Bernal, Paloma Ramos, and Bianca Guzman examine culturally responsive tools and strategies designed to help empower marginalized students in $\mathrm{K}-12$ computing education over the last two decades. This narrative, systematic review identifies six themes to meet the needs of students in the pursuit of equity.

Given its omnipresence in everyday life, as well as its rapid and perpetual improvement, technology has tremendous potential to impact equity and social justice in the field of education. The articles shared in this special issue offer a glimpse of what is presently being done, as well as what is possible. We hope this issue inspires the creativity, imagination, and social justice pursuits of IJME readers.

\section{References}

Berger, R., Brenick, A., Lawrence, S. E., Coco, L., \& Abu-Raiya, H. (2018). Comparing the effectiveness and durability of contact- and skills-based prejudice reduction approaches. Journal of Applied Developmental Psychology, 59, 46-53. doi: 10.1016/j.appdev.2018.04.002

Chib, A., \& Wardoyo, R. J. (2018). Differential OER impacts of formal and informal ICTs: Employability of female migrant workers. International Review of Research in Open and Distributed Learning, 19(3), 94-113. doi: 10.19173/irrodl.v19i3.3538

Kim, Y., \& Searle, K. (2017). Empowering student voice through interactive design and digital making. Computers in the Schools, 34(3), 142-151. doi: 10.1080/07380569.2017.1348082

Marx, S. (Ed.). (2017). Qualitative research in STEM: Studies of equity, access, and innovation. New York, NY: Routledge. 
Shin, M., Barton, A. C., \& Johnson, L. (2017). "I am an innovator": Quahn's counternarrative of becoming in STEM. In S. Marx (Ed.), Qualitative research in STEM: Studies of equity, access, and innovation (pp. 15-35). New York, NY: Routledge.

\section{Guest Editor Contact}

Sherry Marx: sherry.marx@usu.edu

Utah State University, 2805 Old Main Hill, Logan, UT 84322-2805, U.S.A.

Yanghee Kim: ykim9@niu.edu

Northern Illinois University, Gabel Hall 208, DeKalb, IL 60115 U.S.A 